\title{
Temporal drop of genetic diversity in Bombus pauloensis
}

\author{
Kevin Maebe ${ }^{1}$, Marina Haramboure ${ }^{1,2}$, Mariano Lucia ${ }^{3}$, Lepoldo Jésus Alvarez ${ }^{3}$, \\ Guy SMAGGHE ${ }^{1}$ \\ ${ }^{1}$ Department of Plants and Crops, Faculty of Bioscience Engineering, Ghent University, Coupure links 653, B-9000, \\ Ghent, Belgium \\ ${ }^{2}$ Centro de Estudios Parasitológicos y de Vectores (CEPAVE), CONICET-UNLP, Boulevard 120 s/n, 1900, La Plata, \\ Buenos Aires, Argentina \\ ${ }^{3}$ División Entomología, Museo de La Plata, Universidad Nacional de La Plata, Edificio Anexo Museo, Unidades de \\ Investigación FCNyM, CONICET, 122 y 60, 1900FWA, La Plata, Argentina
}

Received 28 February 2019 - Revised 13 May 2019 - Accepted 4 June 2019

\begin{abstract}
Bumblebees are economically important insects which perform essential pollination tasks in natural and managed ecosystems. Recent research studying Neotropical bumblebee species in Brazil showed a clear decrease in genetic diversity over time in Bombus pauloensis. A new temporal assessment of genetic diversity is needed to know whether this was a location-specific result, or a more general phenomenon. This knowledge is essential to be able to prioritize conservation and management needs. Here, the genetic variability of $B$. pauloensis populations in Argentina was investigated over time using museum collection specimens from 1933 to 2016, and compared with reanalyzed data from Brazilian populations. Furthermore, specific time series were made for two Argentinean locations, Candelaria and La Plata, and compared with the time series of Porto Alegre (Brazil). All collected specimens were genotyped with 16 microsatellite loci to estimate genetic diversity parameters. Our results showed no drop in either allelic richness or expected heterozygosity over all Argentinean populations. However, a clear drop in genetic diversity was observed in two out of three location-specific time series. This loss of diversity will have negative impacts on population survival, especially over longer periods of time. Furthermore, the use and release of mass-reared specimens of $B$. pauloensis, which may be inbred and specifically selected for certain commercial but non-adaptive traits, could further diminish the genetic pool. Thus, our result implies the urgent need for regional conservation policies of B. pauloensis in South Brazil and North Argentina.
\end{abstract}

\section{bee decline / genetic diversity / microsatellites / Bombus pauloensis / South America}

\section{INTRODUCTION}

Bumblebees are economically important insects worldwide in natural ecosystems, and also in managed ecosystems. Around 26 bumblebee species are native to South America. Both Argentinean and Brazilian faunas harbor eight native species (Abrahamovich et al. 2001; 2007; Cameron et al.

Corresponding author: G. Smagghe, guy.smagghe@ugent.be Manuscript editor: Klaus Hartfelder
2007; Santos Júnior et al. 2015; Françoso et al. 2016). In both countries, Bombus (Thoracobombus) pauloensis, formerly named Bombus atratus Franklin, 1913 (Moure and Melo 2012), generally is the most abundant and widely distributed species (Abrahamovich et al. 2007; Martins and Melo 2010). As with Bombus terrestris in Europe, Bombus impatiens in Northern America, and Bombus ignitus in China, B. pauloensis is commercially reared for the South American market to perform pollination services essential to improving plant production of diverse crops under cover (Cruz et al. 2007, 2008). 
In the Neotropical region, bumblebees are showing major population declines due to the invasion of non-native bumblebee species with hitchhiking parasites, and the ongoing and continuous destruction of suitable habitat (Freitas et al. 2009; Martins et al. 2013; Arbetman et al. 2013; Schmid-Hempel et al. 2014). Recent research shows temporal losses of genetic diversity in Bombus morio and B. pauloensis populations from Southern Brazil (Maebe et al. 2018). These results can have strong conservation implications as populations with lower genetic diversity levels are more susceptible to diseases (Cameron et al. 2007; Whitehorn et al. 2011; 2014), and have a more limited potential to adapt to, and thus survive, future environmental changes (Frankham 2005; Zayed 2009; Habel et al. 2014). However, whether the result of genetic pauperization was a location-specific result or a more general phenomenon is not yet known. A temporal assessment of genetic diversity is needed to gain knowledge which would enable us to prioritize conservation and management needs.

Here, the temporal stability of genetic diversity was investigated in the widespread South American bumblebee species $B$. pauloensis . Museum collection materials were selected from five locations, and 16 microsatellite (MS) loci were used to genotype those sampled specimens. South Brazilian B. pauloensis specimens described in Maebe et al. (2018), together with one addition population from São Francisco de Paula, were reanalyzed with the same 16 microsatellites to allow comparison of genetic diversity. As genetic diversity parameters, both allelic richness and expected heterozygosity were estimated. For two Argentinean locations (Candelaria and La Plata), time series were made from 1946 to 2012, and compared with the time series from Porto Alegre in Brazil (Maebe et al. 2018). Our results should bring more insight into the occurrence of temporal changes in genetic diversity, and gain knowledge for future conservation and management measures.

\section{MATERIAL AND METHODS}

\subsection{Specimen collection}

Historical B. pauloensis specimens were originally collected from five Argentinean locations and were retrieved from the Museo de La Plata (MLP), Argentina, and the Centro de Estudios Parasitológicos y de Vectores (CEPAVE) (Figure 1). The data from these locations will be compared with the reanalyzed data obtained from a recent study (Maebe et al. 2018) in which B. pauloensis specimens from several locations in Brazil were genotyped with the same $16 \mathrm{MS}$ (Figure 1), together with 25 extra specimens collected from an additional location (São Francisco de Paula, 1996-1997) from the Museum of Science and Technology at Pontificia Universidade Católica do Rio Grande de Sul (PUCRS). The data of Brazilian B. pauloensis had to be reanalyzed as the data described in Maebe et al. (2018) were based on only 14 MS loci. In the latter study, removal of 2 MS loci (BT08 and 0294) was necessary to be able to compare the obtained genetic diversity parameters for $B$. pauloensis with those obtained from another bumblebee species, B. morio, for which these two loci could not be reliably amplified.

Furthermore, time series were made for two Argentinean locations: two time periods for La Plata (LaP), 1985-1987 and 2016; and three time periods for Candelaria (Cand), 1946-1959, 1985-1986, and 2007-2012. These time series were compared with the time series of Porto Alegre (PA, Brazil), including four time periods: 1946-1959, 19911994, 1999-2004, and 2007-2012 (see Maebe et al. 2018).

\subsection{DNA extraction and genotyping protocol}

Individual DNA extractions were performed on one middle leg following a Chelex protocol as described in Maebe et al. (2013). Afterwards, each specimen was genotyped with 16 microsatellite loci which showed reliable signals in previous research with bumblebee collection material (Maebe et al. 2015, 2016, 2018; Table I). MS loci were amplified by multiplex PCR in $10 \mu \mathrm{l}$ using the Type-it QIAGEN PCR kit. Per sample, four multiplex reactions were performed each containing 1.33- $\mu$ l template DNA, Type-it Multiplex PCR Master Mix (2×, Qiagen), and four forward and reverse primers (Maebe et al. 2016, 2018; 


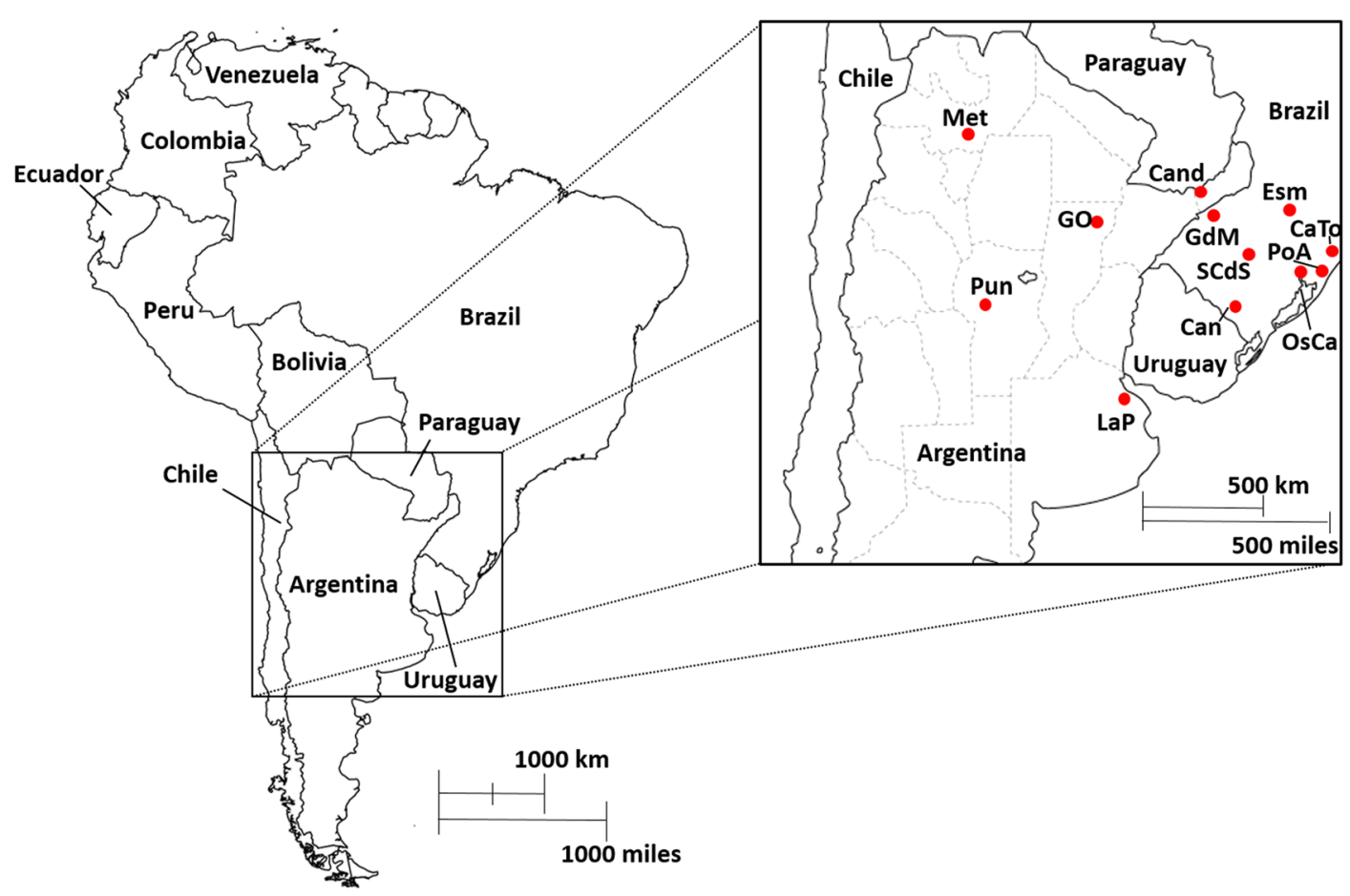

Figure 1. Overview of the sampling locations of B. pauloensis in Argentina and South Brazil. Argentinean sampling locations were La Plata (LaP), Candelaria (Cand), Metan (Met), General Obligado (GO), and Punilla (Pun). Brazilian sampling locations were Esmeralda (Esm), Candiota (Can), Guarani das Missões (GdM), São Francisco de Paula (SFdP), Santa Cruz do Sul (SCdS), Cambará do Sul and Torres (CaTo), Osório and Capão da Canoa (OsCa), and Porto Alegre (POA).

Table I). PCR protocol, capillary electrophoresis, and fragment scoring were done as described in Maebe et al. (2013).

\subsection{Data validation and genetic diversity}

Before data analysis, several genotyped individuals which could not be scored in a reliable manner for at least 12 loci, and all detected sisters using Colony 2.0 (Wang 2004) with 5\% genotyping error correction per locus, and Kinalyzer (Ashley et al. 2009) using the 2-allele algorithm and consensus method, were excluded. Furthermore, genotypic linkage disequilibrium, deviations from Hardy-Weinberg (HW) equilibrium, and presence of null alleles were tested using Fstat 2.9.3 (Goudet 2001), GenAlEx 6.5 (Peakall and Smouse 2006), and Microchecker (Van Oosterhout et al. 2004), respectively.
Estimations of Nei's unbiased expected heterozygosity $\left(H_{\mathrm{E}}\right.$, Nei 1978) and the sample sizecorrected private allelic richness $\left(A_{\mathrm{R}}\right)$ normalized to 10 diploid specimens were performed with GenAlEx 6.5 (Peakall and Smouse 2006) and Hp-Rare 1.1 (Kalinowski 2002), respectively. Linear mixed models (LMMs) were performed for both genetic diversity parameters $\left(A_{\mathrm{R}}\right.$ and $H_{\mathrm{E}}$ ) in RStudio (R Development Core Team 2008) with $\mathrm{R}$ package lme4 version 1.1-10 (Bates et al. 2015). Models started with location and time period as fixed factors and microsatellite loci as random factor to account for inter-locus variability (Soro et al. 2017). The best-fitting model was selected based on Akaike's information criterion (AIC) obtained by using the dredge command within the MUMIn package (Barton 2015; Maebe et al. 2016). Selected LMMs were run, main effects determined, and marginal and conditional coefficients of determination 
Table I. List of microsatellite primers and multiplexes used for characterization of Brazilian and Argentinean B. pauloensis

\begin{tabular}{|c|c|c|c|}
\hline Locus & Dye & Forward primer & Reverse primer \\
\hline \multicolumn{4}{|c|}{ Multiplex $1\left(T_{\mathrm{a}}=52^{\circ} \mathrm{C}\right)$} \\
\hline BL13 & PET & CGAATGTTGGGATTTTCGTG & GCGAGTACGTGTACGTGTTCTATG \\
\hline BT02 & NED & AGGAACCGAGCGATAGAACCAC & GCTTTGCCTTTCCATCTTGCTG \\
\hline BT23 & FAM & GCAACAGAAAATCGTCGGTAGTG & GCGGCAATAAAGCAATCGG \\
\hline BT24 & VIC & TCTTTCCGTTTTCCCCCTG & CACCCACTTACATACATACACGCTC \\
\hline \multicolumn{4}{|c|}{ Multiplex $2\left(T_{\mathrm{a}}=52^{\circ} \mathrm{C}\right)$} \\
\hline BL02 & NED & GAACAGTGAGAGCGAGGAACAGAG & TTGCCACGTATATCCGAGCGAACC \\
\hline BT04 & FAM & GAGAGAGATCGAATGGTGAGAGC & TGAGCACGTTCTTTCGTTCAC \\
\hline BT08 & PET & AGAACCTCCGTATCCCTTCG & AGCCTACCCAGTGCTGAAAC \\
\hline BT10 & VIC & TCTTGCTATCCACCACCCGC & GGACAGAAGCATAGACGCACCG \\
\hline \multicolumn{4}{|c|}{ Multiplex $3\left(T_{\mathrm{a}}=49^{\circ} \mathrm{C}\right)$} \\
\hline B100 & FAM & CGTCCTCGTATCGGGCTAAC & CGTGGAAACGTCGTGACG \\
\hline B11 & NED & GCAACGAAACTCGAAATCG & GTTCATCCAAGTTTCATCCG \\
\hline B126 & PET & GCTTGCTGGTGAATTGTGC & CGATTCTCTCGTGTACTCC \\
\hline B1232 & VIC & GAAATTCGTGCGGAGGG & CAGAGAACTACCTAGTGCTACGC \\
\hline \multicolumn{4}{|c|}{ Multiplex $4\left(T_{\mathrm{a}}=52^{\circ} \mathrm{C}\right)$} \\
\hline 0294 & FAM & AGTACGATAAAGCCAGGAAAG & TGTATGCCTATTGTACGAGTGT \\
\hline 0304 & NED & GTATGAGTGAGTGATGTGCAAG & СССТTCATCTCTGAACAATATC \\
\hline 0810 & PET & TTAACAAATCCGAATTTAAAGG & GATAGTGGTTGCTTGTCATCTT \\
\hline BT05 & VIC & TTTCCTATGCCGAACGTCACC & CCCAGATAAAAGACCGCCTCTAGTC \\
\hline
\end{tabular}

computed (Nakagawa and Schielzeth 2013; Soro et al. 2017). Temporal stability of genetic diversity was investigated by Tukey HSD post hoc comparisons using the R package multcomp (Hothorn et al. 2008) as described in Soro et al. (2017).

Data availability The genotype of each specimen, based on our set of 16 microsatellite loci, will be archived at DRYAD: doi:https://doi.org/10.5061 /dryad.3sc3c6p.

\section{RESULTS}

\subsection{Data analysis}

Of the 291 specimens in total, 129 were collected from the Argentinean museum collection and 162 from Brazilian museum collections (see also Maebe et al. 2018), which were analyzed and reanalyzed with 16 microsatellite loci, respectively. In total, 107 specimens were removed from further analysis (Table II), which consisted of 83 full-sibs detected with Colony 2.0 and Kinalyzer, and 24 specimens with too much missing data (for 5 loci or more). For the remaining 74 Argentinean and 110 Brazilian specimens (Table II), all 16 loci could be scored reliably and no significant linkage disequilibrium was found. Heterozygote deficits and excesses were detected in Hardy-Weinberg equilibrium (HWE) tests. These deviations may be due to the presence of low frequencies of null alleles $(<5 \%$ for all loci), the low sample sizes, or the fact that populations consisted of samples collected over several years and thus over multiple generations.

\subsection{Genetic diversity estimations}

The allelic richness $\left(A_{\mathrm{R}}\right)$ ranged from 2.113 ( $\mathrm{SE} \pm 0.252$ ) to 3.175 ( $\mathrm{SE} \pm 0.511$ ), with a mean $A_{\mathrm{R}}$ of 2.685 ( $\mathrm{SE} \pm 0.117$; Table III) for the 
Table II. Number of B. pauloensis specimens genotyped in the analysis categorized per country. With $N$ the total number of specimens genotyped, Missing data number of not amplifiable specimens, Sisters number of removed full sibs, and $N$ final actual number of workers used in all further analyses. Argentinean sampling locations were LaP La Plata, Cand Candelaria, Met Metan, GO General Obligado, Pun Punilla. Brazilian sampling locations were Esm Esmeralda, Can Candiota, GdM Guarani das Missões, $S F d P$ São Francisco de Paula, $S C d S$ Santa Cruz do Sul, CaTo Cambará do Sul and Torres, $O S C a$ Osório and Capão da Canoa, POA Porto Alegre

\begin{tabular}{|c|c|c|c|c|c|c|}
\hline Country & Code & Time period & $N$ & Sisters & Missing data & $N$ final \\
\hline \multirow[t]{9}{*}{ Argentina } & Met & 1933 & 9 & 3 & 0 & 6 \\
\hline & Cand & 1946-1959 & 10 & 4 & 0 & 6 \\
\hline & GO & 1946-1959 & 39 & 24 & 3 & 12 \\
\hline & Pun & 1985-1987 & 11 & 5 & 0 & 6 \\
\hline & $\mathrm{LaP}$ & $1985-1987$ & 30 & 9 & 0 & 21 \\
\hline & Cand & 1985-1987 & 10 & 3 & 0 & 7 \\
\hline & Cand & 2007 & 10 & 2 & 0 & 8 \\
\hline & $\mathrm{LaP}$ & 2016 & 10 & 2 & 0 & 8 \\
\hline & Subtotal & & 129 & 52 & 3 & 74 \\
\hline \multirow[t]{13}{*}{ Brazil } & PoA & 1946-1959 & 13 & 0 & 8 & 5 \\
\hline & PoA & 1991-1994 & 8 & 1 & 1 & 6 \\
\hline & CaTo & 1991-1994 & 6 & 0 & 1 & 5 \\
\hline & OsCa & 1991-1994 & 9 & 0 & 4 & 5 \\
\hline & SFdP & 1996-1997 & 25 & 7 & 3 & 15 \\
\hline & Can & 1999-2004 & 19 & 13 & 0 & 6 \\
\hline & PoA & 1999-2004 & 6 & 0 & 0 & 6 \\
\hline & SCdS & 1999-2004 & 8 & 0 & 2 & 6 \\
\hline & Esm & 2010-2012 & 22 & 4 & 1 & 17 \\
\hline & GdM & 2010-2012 & 33 & 4 & 1 & 28 \\
\hline & PoA & 2010-2012 & 13 & 2 & 0 & 11 \\
\hline & Subtotal & & 162 & 31 & 21 & 110 \\
\hline & Total & & 291 & 83 & 24 & 184 \\
\hline
\end{tabular}

Argentinean populations. Per population, the expected heterozygosity $\left(H_{\mathrm{E}}\right)$ ranged from 0.300 ( $\mathrm{SE} \pm 0.071)$ to 0.492 ( $\mathrm{SE} \pm 0.083$; Table III). Mean genetic diversity parameters in the Brazilian populations using $16 \mathrm{MS}$ were higher than those described within Maebe et al. (2018) based on "only" $14 \mathrm{MS}\left(A_{\mathrm{R}}=3.213\right.$ and $H_{\mathrm{E}}=0.474$ versus $A_{\mathrm{R}}=2.313$ and $H_{\mathrm{E}}=0.458$, respectively). A comparison between Argentinean and Brazilian populations revealed significantly lower mean $A_{\mathrm{R}}$ estimations in Argentinean B. pauloensis populations (Student $t$ tests, df $=17, t=2.944$, $p=0.009$ ) but not for mean $H_{\mathrm{E}}$ (Student $t$ tests, $t=0.990, p=0.336 ; A_{\mathrm{R}}$ and $H_{\mathrm{E}}$, respectively; Table III; Figure 2).

\subsection{Temporal shifts in genetic diversity of B. pauloensis populations}

The best-fitting LMMs for $A_{\mathrm{R}}$ and $H_{\mathrm{E}}$ based on the AIC score included "time period" as a fixed factor in the Brazilian B. pauloensis populations (delta $>2$; Table IV). The importance of time period within the model could also be seen by comparing the model with and without time period as a factor (LRT, $A_{\mathrm{R}}, \chi^{2}=10.995$, $\mathrm{df}=4, p=0.027$; and $H_{\mathrm{E}}, \chi^{2}=28.527, \mathrm{df}=4$, $p<0.001$, respectively). As expected, genetic diversity dropped over time (see Maebe et al. 2018, Table II; Figure 2). However, another pattern was observed within the Argentinean 
Table III. Genetic diversity estimated for each B. pauloensis population. The mean values (and SE) of the expected heterozygosity $\left(H_{\mathrm{E}}\right)$, the observed heterozygosity $\left(H_{\mathrm{O}}\right)$, and the allelic richness $\left(A_{\mathrm{R}}\right)$ over all microsatellite loci are given for each population. With $N$ the number of specimens per population

\begin{tabular}{|c|c|c|c|c|c|c|c|c|c|}
\hline Species & Location & Period & $N$ & $A_{\mathrm{R}} *$ & SE & $H_{\mathrm{O}}$ & SE & $H_{\mathrm{E}}$ & SE \\
\hline \multirow[t]{9}{*}{ Argentina } & Met & 1933 & 6 & 2.791 & 0.378 & 0.302 & 0.068 & 0.430 & 0.078 \\
\hline & Cand & 1946-1959 & 6 & 3.175 & 0.511 & 0.479 & 0.103 & 0.492 & 0.083 \\
\hline & GO & 1946-1959 & 12 & 2.113 & 0.252 & 0.246 & 0.066 & 0.300 & 0.061 \\
\hline & Pun & 1985-1987 & 6 & 2.299 & 0.277 & 0.465 & 0.098 & 0.397 & 0.071 \\
\hline & $\mathrm{LaP}$ & 1985-1987 & 21 & 2.609 & 0.429 & 0.154 & 0.039 & 0.361 & 0.087 \\
\hline & Cand & 1985-1987 & 7 & 3.059 & 0.456 & 0.363 & 0.067 & 0.471 & 0.078 \\
\hline & Cand & 2007 & 8 & 2.778 & 0.438 & 0.320 & 0.085 & 0.365 & 0.088 \\
\hline & $\mathrm{LaP}$ & 2016 & 8 & 2.653 & 0.492 & 0.375 & 0.098 & 0.368 & 0.091 \\
\hline & & Mean & 9.25 & 2.685 & 0.117 & 0.338 & 0.036 & 0.398 & 0.021 \\
\hline \multirow[t]{12}{*}{ Brazil } & PoA & 1946-1959 & 5 & 3.063 & 0.438 & 0.392 & 0.075 & 0.625 & 0.078 \\
\hline & PoA & 1991-1994 & 6 & 2.903 & 0.393 & 0.439 & 0.095 & 0.444 & 0.082 \\
\hline & CaTo & 1991-1994 & 5 & 3.063 & 0.359 & 0.274 & 0.039 & 0.526 & 0.072 \\
\hline & OsCa & 1991-1994 & 5 & 3.750 & 0.534 & 0.531 & 0.083 & 0.583 & 0.079 \\
\hline & SFdP & 1996-1997 & 15 & 3.647 & 0.430 & 0.429 & 0.066 & 0.532 & 0.072 \\
\hline & Can & 1999-2004 & 6 & 3.525 & 0.532 & 0.406 & 0.087 & 0.499 & 0.077 \\
\hline & PoA & 1999-2004 & 6 & 3.046 & 0.442 & 0.365 & 0.091 & 0.432 & 0.078 \\
\hline & SCdS & 1999-2004 & 6 & 2.811 & 0.401 & 0.219 & 0.058 & 0.418 & 0.083 \\
\hline & Esm & 2010-2012 & 17 & 2.956 & 0.469 & 0.411 & 0.102 & 0.396 & 0.089 \\
\hline & GdM & 2010-2012 & 28 & 3.047 & 0.522 & 0.359 & 0.087 & 0.395 & 0.091 \\
\hline & PoA & 2010-2012 & 11 & 2.846 & 0.556 & 0.369 & 0.098 & 0.368 & 0.095 \\
\hline & & Mean & 10.00 & 3.213 & 0.107 & 0.381 & 0.024 & 0.474 & 0.024 \\
\hline
\end{tabular}

*Allelic richness calculated based on 10 diploid specimens

B. pauloensis populations (Figure 2). Indeed, for both $A_{\mathrm{R}}$ and $H_{\mathrm{E}}$, best-fitting LMMs were with "location" as a fixed factor but without time period as a fixed factor (delta $>2$; Table IV). That time period has no effect on the best model can be seen in comparing the model with and without time period as a factor (LRT, $A_{\mathrm{R}}, \chi^{2}=0.406, \mathrm{df}=4, p=0.982$; and $H_{\mathrm{E}}, \chi^{2}=1.367, \mathrm{df}=4, p=0.850$, respectively). So, overall, in Argentinean populations,
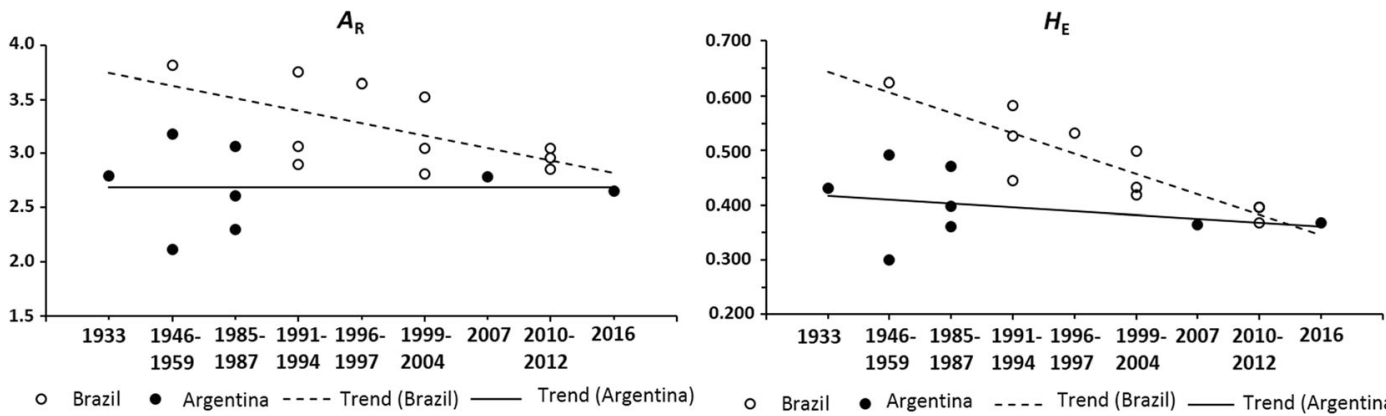

Figure 2. Comparison of temporal shifts in mean $A_{\mathrm{R}}$ and $H_{\mathrm{E}}$ between Argentinean and Brazilian B. pauloensis populations. 
Table IV. Best-fitting model explaining the patterns in genetic diversity parameters $A_{\mathrm{R}}$ and $H_{\mathrm{E}}$. Based on their high (negative or positive) Akaike's information criterion (AIC), only the best models fitting linear mixed effect models (with a delta $<2+1$ ) are given using only the Brazilian (A) and Argentinean populations' (B) and (C) the populationspecific time series. With + parameters included in the model, $N A$ not included parameters, and best models in italic.

\begin{tabular}{|c|c|c|c|c|c|c|c|c|c|c|}
\hline \multirow[t]{7}{*}{ A } & $A_{\mathrm{R}}$ & (Intercept) & Location & Period & Location:period & df & $\log \operatorname{Lik}$ & AIC & Delta & Weight \\
\hline & $M 2$ & 3.813 & $N A$ & + & $N A$ & 7 & -283.930 & 582.5 & 0.00 & 0.553 \\
\hline & M1 & 3.219 & $N A$ & $N A$ & $N A$ & 3 & -289.407 & 585.0 & 2.43 & 0.164 \\
\hline & $H_{\mathrm{E}}$ & (Intercept) & Location & Period & Location:period & df & $\log$ Lik & AIC & Delta & Weight \\
\hline & $M 2$ & 0.625 & $N A$ & + & $N A$ & 7 & 35.111 & -55.6 & 0.00 & 0.890 \\
\hline & M4 & 0.687 & + & + & $N A$ & 13 & 39.116 & -50.0 & 5.57 & 0.055 \\
\hline & M8 & 0.687 & + & + & + & 13 & 39.116 & -50.0 & 5.57 & 0.055 \\
\hline \multirow[t]{8}{*}{ B } & $A_{\mathrm{R}}$ & (Intercept) & Location & Period & Location:period & df & $\log \operatorname{Lik}$ & AIC & Delta & Weight \\
\hline & M3 & 2.789 & + & $N A$ & $N A$ & 7 & -199.857 & 414.6 & 0.00 & 0.797 \\
\hline & M1 & 2.684 & $N A$ & $N A$ & $N A$ & 3 & -206.303 & 418.8 & 4.15 & 0.100 \\
\hline & $H_{\mathrm{E}}$ & (Intercept) & Location & Period & Location:period & $\mathrm{df}$ & $\log \mathrm{Lik}$ & AIC & Delta & Weight \\
\hline & $M 1$ & 0.398 & $N A$ & $N A$ & $N A$ & 3 & 2.590 & 1.0 & 0.00 & 0.540 \\
\hline & $M 3$ & 0.430 & + & $N A$ & $N A$ & 7 & 6.397 & 2.1 & 1.13 & 0.308 \\
\hline & M4 & 0.430 & + & + & $N A$ & 10 & 8.378 & 5.1 & 4.11 & 0.069 \\
\hline & M8 & 0.430 & + & + & + & 10 & 8.378 & 5.1 & 4.11 & 0.069 \\
\hline \multirow[t]{8}{*}{$\mathrm{C}$} & $A_{\mathrm{R}}$ & (Intercept) & Location & Period & Location:period & $\mathrm{df}$ & $\log \mathrm{Lik}$ & AIC & Delta & Weight \\
\hline & $M 2$ & 3.494 & $N A$ & + & $N A$ & 6 & -231.793 & 476.2 & 0.00 & 0.595 \\
\hline & M4 & 3.228 & + & + & $N A$ & 8 & -230.644 & 478.3 & 2.15 & 0.203 \\
\hline & M3 & 2.631 & + & $N A$ & $N A$ & 5 & -234.538 & 479.5 & 3.31 & 0.114 \\
\hline & $H_{\mathrm{E}}$ & (Intercept) & Location & Period & Location:period & $\mathrm{df}$ & $\operatorname{logLik}$ & AIC & Delta & Weight \\
\hline & M2 & 0.558 & $N A$ & + & $N A$ & 6 & 19.256 & -25.9 & 0.00 & 0.637 \\
\hline & M4 & 0.511 & + & + & $N A$ & 8 & 20.520 & -24.0 & 1.92 & 0.244 \\
\hline & M8 & 0.625 & + & + & $N A$ & 11 & 23.255 & -22.5 & 3.38 & 0.118 \\
\hline
\end{tabular}

genetic diversity remained fairly stable over time. However, location played a significant role, as Candelaria (Cand) had a significantly higher genetic diversity in comparison with General Obligado (GO) and La Plata (LaP) ( $A_{\mathrm{R}}$ and $H_{\mathrm{E}}$; Tukey HSD post hoc test comparisons, $p<0.05)$, and for $A_{\mathrm{R}}$ also with Punilla (Pun) (Tukey HSD post hoc test comparisons, $p<0.05$; Table V).

\subsection{Temporal shifts in genetic diversity present in the three time series?}

As location can play a significant role in patterns of genetic diversity (see Table IVB and Table V), we specifically investigated genetic diversity over time in only those locations having clear time series. In these location- specific time series, the factor time period actually played an important role in the model (delta $>2$; Table IV and $A_{\mathrm{R}}$ and $H_{\mathrm{E}}$; LRT, $\chi^{2}=10.293, \mathrm{df}=3, p=0.016$ and $\chi^{2}=$ 19.159, df $=3, p<0.001$, respectively). The drop of $A_{\mathrm{R}}$ and $H_{\mathrm{E}}$ over time in these populations is visualized in Figure 3. Multiple comparisons of time periods showed significantly lower levels of genetic diversity, especially those in comparison with time period 19461959 (Tukey HSD post hoc test comparisons, $p<0.05$; Table V).

\section{DISCUSSION}

Recent research described the loss of genetic diversity over time within Brazilian populations of B. pauloensis (Maebe et al. 2018). 
Table V. Output of the different factors in the linear mixed models (LMMs) on $A_{\mathrm{R}}$ and $H_{\mathrm{E}}$. (A) in only the Argentinian B. pauloensis populations; and (B) in the location-specific time series. After $t$ tests and for each factor or interaction, the estimate, standard error (SE), and $p$ value are shown. Significant factors in italics

\begin{tabular}{|c|c|c|c|c|}
\hline \multicolumn{5}{|l|}{ A. Argentina } \\
\hline$A_{\mathrm{R}}$ & Estimate & SE & $t$ value & $p$ \\
\hline Met vs Pun & -0.447 & 0.481 & -0.929 & 0.353 \\
\hline Met vs GO & -0.748 & 0.589 & -1.271 & 0.204 \\
\hline Met vs LaP & -0.136 & 0.340 & -0.401 & 0.689 \\
\hline Met vs Cand & 0.314 & 0.481 & 0.654 & 0.513 \\
\hline Pun vs GO & -0.186 & 0.361 & -0.514 & 0.607 \\
\hline Pun vs LaP & 0.333 & 0.313 & 1.064 & 0.287 \\
\hline Pun vs Cand & 0.706 & 0.295 & 2.394 & 0.017 \\
\hline GO vs LaP & 0.518 & 0.289 & 1.794 & 0.073 \\
\hline GO vs Cand & 0.892 & 0.272 & 3.272 & 0.001 \\
\hline $\mathrm{LaP}$ vs Cand & 0.373 & 0.164 & 2.269 & 0.023 \\
\hline$H_{\mathrm{E}}$ & Estimate & SE & $t$ value & $p$ \\
\hline Met vs Pun & -0.026 & 0.096 & -0.274 & 0.784 \\
\hline Met vs GO & -0.144 & 0.118 & -1.224 & 0.221 \\
\hline Met vs LAP & -0.062 & 0.069 & -0.917 & 0.359 \\
\hline Met vs Cand & 0.048 & 0.096 & 0.496 & 0.620 \\
\hline Pun vs GO & -0.097 & 0.073 & -1.335 & 0.182 \\
\hline Pun vs LaP & -0.033 & 0.063 & -0.518 & 0.604 \\
\hline Pun vs Cand & 0.045 & 0.059 & 0.763 & 0.445 \\
\hline GO vs LaP & 0.065 & 0.059 & 1.088 & 0.276 \\
\hline GO vs Cand & 0.143 & 0.056 & 2.551 & 0.011 \\
\hline $\mathrm{LaP}$ vs Cand & 0.078 & 0.034 & 2.301 & 0.021 \\
\hline \multicolumn{5}{|l|}{ B. Location specific } \\
\hline$A_{\mathrm{R}}$ & Estimate & SE & $t$ value & $p$ \\
\hline (1946-1959) vs (1985-1994) & -0.636 & 0.230 & -2.767 & 0.006 \\
\hline (1946-1959) vs (1999-2004) & -0.422 & 0.303 & -1.392 & 0.164 \\
\hline (1946-1959) vs (2007-2016) & -0.735 & 0.230 & -3.195 & 0.001 \\
\hline (1985-1994) vs (1999-2004) & 0.210 & 0.219 & 0.960 & 0.337 \\
\hline (1985-1994) vs (2007-2016) & -0.098 & 0.158 & -0.623 & 0.533 \\
\hline (1999-2004) vs (2007-2016) & -0.298 & 0.194 & -1.538 & 0.124 \\
\hline$H_{\mathrm{E}}$ & Estimate & SE & $t$ value & $p$ \\
\hline (1946-1959) vs (1985-1994) & -0.133 & 0.041 & -3.263 & 0.001 \\
\hline (1946-1959) vs (1999-2004) & -0.116 & 0.054 & -2.161 & 0.031 \\
\hline (1946-1959) vs (2007-2016) & -0.191 & 0.041 & -4.706 & $<0.001$ \\
\hline (1985-1994) vs (1999-2004) & 0.017 & 0.039 & 0.436 & 0.663 \\
\hline (1985-1994) vs (2007-2016) & -0.056 & 0.028 & -2.106 & 0.035 \\
\hline (1999-2004) vs (2007-2016) & -0.072 & 0.035 & -2.085 & 0.037 \\
\hline
\end{tabular}

The authors found a decrease of $A_{\mathrm{R}}(26.65 \%)$ and $H_{\mathrm{E}}(40.14 \%)$ from 1946 until 2012 (see also Figure 2). However, it remained unclear if the temporal drop in genetic diversity was a location-specific result, or if all populations of this species undergo such dramatic losses. 

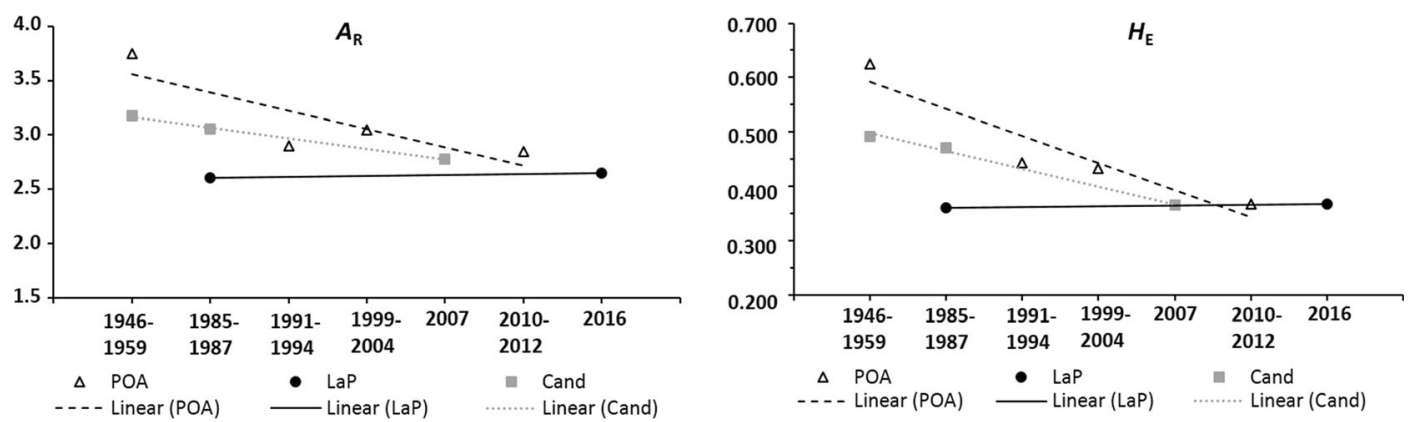

Figure 3. Temporal shift in mean $A_{\mathrm{R}}$ and $H_{\mathrm{E}}$ between location-specific time series. Argentinean locations: La Plata (LaP) and Candelaria (Cand). Brazilian location: Porto Alegre (POA).

Additional research is needed to make the distinction between both possibilities, which in turn is essential to prioritize more local conservation and management needs or specific measurements spanning over the species' full distribution range. Therefore, we performed in this study a temporal assessment of genetic diversity of B. pauloensis in Argentina and compared it with the reanalyzed Brazilian data (Maebe et al. 2018). Firstly, the reanalyzed data of the Brazilian populations confirmed the drop in genetic diversity over time (Table IVA). However, when analyzing the genetic variability in the Argentinean populations of B. pauloensis, no such pattern was observed (Figure 2). Indeed, as time period was not significantly affecting the model (Table IVB), our data showed that genetic diversity remained temporally stable within the Argentinean B. pauloensis populations. Hence, location was significantly affecting the model. Therefore, we searched for the temporal effect of genetic diversity in location-specific time periods. Our results showed a clear drop in genetic diversity observed over time in Candelaria (Argentina) and Porto Alegre (Brazil) (Figure 3). Although for La Plata no drop could be detected, the lack of old pre-1980 specimens could be a possible explanation for the latter result. Additional time points could bring more light to this question.

In general, our results showed a locationspecific loss of genetic diversity over time in South American B. pauloensis populations. This will have negative impacts on population survival of this supposed stable species (Martins and Melo 2010). Indeed, populations with low genetic diversity can become more vulnerable to diseases and pathogens (Whitehorn et al. 2011; Cameron et al. 2011). If these populations become small, genetic diversity may decrease further due to an increased impact of genetic drift. Furthermore, due to an increased change of brother-sister mating, inbreeding and inbreeding depression may worsen the situation (Frankham 2005; Zayed 2009; Habel et al. 2014). If these populations also become isolated, gene flow will decrease, and this will cause a further loss of genetic variability. Furthermore, the use and release of massreared specimens of $B$. pauloensis, which may be inbred and specifically selected for certain non-adaptive traits, could also contribute to the genetic pauperization of the local B. pauloensis populations. In general, these all will have a negative impact on population viability and these populations' potential to adapt to current and future changes in the environment (Frankham 2005; Zayed 2009, Habel et al. 2014).

What could have caused the loss of genetic diversity in Brazilian B. pauloensis populations and why it is only present at specific locations in Argentina are not known. Land use changes in South Brazil and Northeast Argentina, with strong agricultural expansions and increases in urban regions, could have caused the reduction in genetic diversity as they have led to the population decline of another Neotropical bumblebee species, B. bellicosus (Martins et al. 2013). Temporal differences in the impact of these drivers may explain the local differences in detection of a 
reduction over time between Argentinean and Brazilian B. pauloensis populations. As genetic diversity was significantly lower in Argentinean populations, maybe the major losses in genetic diversity happened earlier in time, while this phenomenon is only recently present in Brazil. Hence, Maebe et al. (2018) mentioned recent deforestation events as a possible explanation for the reduced genetic diversity levels in South Brazil (Hansen et al. 2013), especially as this was the major difference between South Brazil, where losses of genetic diversity were observed, and mainland Europe where no drop in genetic diversity has been observed over the last century (Maebe et al. 2016). Differences in deforestation rates and history between locations could maybe also explain the local differences between South American B. pauloensis populations. Further research is needed to find if recent deforestation events are indeed causing shifts in genetic diversity levels in $B$. pauloensis populations and bumblebees in general, especially now that bees also face an additional stressor-climate change. The latter could cause shifts in suitable climatic conditions, as is already been shown for $B$. bellicosus within the same region as our study (Martins et al. 2015). This additional driver may play a role in the further genetic pauperization of these already-vulnerable populations. More studies are necessary to broaden our knowledge on how climate change can and will affect local bumblebee populations. In general, our result implies the urgent need for conservation of B. pauloensis and Neotropical bumblebees in general.

\section{ACKNOWLEDGMENTS}

The authors would like to thank both Eline Devoldere and Lies Vanryckeghem for their help in performing all necessary lab work. Furthermore, we acknowledge Alexandra Hart for proofreading the manuscript. Finally, we thank two anonymous reviewers for their comments and remarks which helped us increase the quality of our manuscript.

\section{AUTHORS' CONTRIBUTION}

MH collected all Argentinean specimens. ML and JLA curated and helped collect the collection specimens. MH performed the experiments. KM and $\mathrm{MH}$ designed the study. KM performed the analysis, drafted the manuscript, and designed the figures. All authors contributed to the writing of the paper.Funding information

This study was financially supported by the Research Foundation-Flanders (FWO-Vlaanderen; G042618N), the Belgian Science Policy (BELSPO; BR/132/A1/BELBEES), and the Agencia Nacional de Promoción Científica y Tecnológica, Argentina (PICT 2016-0289). ML and LA are financially supported by Consejo Nacional de Investigaciones Científicas y Técnicas, Argentina (CONICET).

Baisse temporelle de la diversité génétique de Bombus pauloensis

Déclin des abeilles / diversité génétique / microsatellites / Bombus pauloensis

Amérique du Sud Zeitweiliger Verlust der genetischen Diversität bei Bombus pauloensis

Rückgang von Bienen / genetische Diversität / Mikrosatelliten / Bombus pauloensis / Südamerika

\section{REFERENCES}

Abrahamovich, A., Díaz, N., Lucia, M. (2007) Identificación de las "abejas sociales" del género Bombus (Hymenoptera, Apidae) presentes en la Argentina: clave pictórica, diagnosis, distribución geográfica y asociaciones florales. Rev.Fac. Agron. 106 (2), 165-176.

Abrahamovich, A.H., Tellería, M.C., Díaz, N.B. (2001) Bombus species and their associated flora in Argentina. Bee World 82, 76-87.

Arbetman, M.P., Meeus, I., Morales, C.L., Aizen, M.A., Smagghe, G. (2013) Alien parasite hitchhikes to Patagonia on invasive bumblebee. Biol. Invasions, 15 , 489-494.

Ashley, M.V., Caballero, I.C., Chaovalitwongse, W., Das Gupta, B., Govindan, P., et al. (2009) Kinalyzer, a 
computer program for reconstructing sibling groups. Mol. Ecol. Resour. 9, 1127-1131.

Barton, K. (2015) MuMIn: Multi - Model Inference. $\boldsymbol{R}$ package version 1.15.1. (http://CRAN.R - project. org/package=MuMIn).

Bates, D., Maechler, M., Bolker, B., Walker, S. (2015) Fitting Linear Mixed - Effects Models Using lme4. J. Stat. Softw. 67(1), 1-48.

Cameron, S.A., Hines, H.M., Williams, P.H.A. (2007) A comprehensive phylogeny of the bumble bees (Bombus ). Biol. J. Linn. Soc. 91, 161-188.

Cameron, S.A., Lozier, J.D., Strange, J.P., Koch, J.B., Cordes, N., et al. (2011) Patterns of widespread decline in North American bumble bees. Proc. Natl. Acad. Sci. U.S.A. 108, 662-667.

Cruz, P., Almanza, M., Cure, J.R. (2007) Logros y perspectivas de la cría de abejorros del género Bombus en Colombia. Revista Fac. Ciencias B. - UMNG 2, 49-60.

Cruz, P., Escobar, A., Almanza, M., Cure, J.R. (2008) Implementación de mejora para la cría en cautiverio de colonias del abejorro nativo Bombus atratus (Hymenoptera: Apoidea). Revista Revista Fac. Ciencias B. - UMNG 3, 70-83.

Françoso, E., de Oliveira, F.F., Arias, M.C. (2016) An integrative approach identifies a new species of bumblebee (Hymenoptera: Apidae: Bombini) from northeastern Brazil. Apidologie 47, 171-185.

Frankham, R. (2005) Genetics and extinction. Biol.Conserv. 126, 131-140.

Freitas, B.M., Imperatriz-Fonseca, V.L., Medina, L.M., Kleinert, A.D.M.P., Galetto, L., et al. (2009) Diversity, threats and conservation of native bees in the Neotropics. Apidologie 40, 332-346.

Goudet, J. (2001) Fstat: a program to estimate and test gene diversities and fixation indices (version 2.9.3). Updated from Goudet, J (1995): Fstat (version 1.2): a computer program to calculate F - statistics. J. Hered. 86, 485-486.

Habel, J.C., Hisemann, M., Finger, A., Danley, P.D., Zachos, F.E. (2014) The relevance of time series in molecular ecology and conservation biology. Biol. Rev. 89, 484-492.

Hansen, M.C., Potapov, P.V., Moore, R., Hancher, M., Turubanova, S.A. et al. (2013) High-resolution global maps of 21 st-century forest cover change. Science 342 (6160), 850-853. Maps are online available at: https://earthenginepartners.appspot.com/science2013-global-forest (Accessed 25 May 2018).

Hothorn, T., Bretz, F., Westfall, P. (2008) Simultaneous inference in general parametric models. Biom. J. 50, 346-363.

Kalinowski, S.T. (2002) How many alleles per locus should be used to estimate genetic distances? Heredity 88, 62-65.

Maebe, K., Golsteyn, L., Nunes-Silva, P., Blochtein, B., Smagghe, G. (2018) Temporal changes in genetic variability in three bumblebee species from Rio Grande do Sul, South Brazil. Apidologie 49 (3), 415-429.

Maebe, K., Meeus, I., Maharramov, J., Grootaert, P., Michez, D., Rasmont, P., Smagghe, G. (2013) Microsatellite analysis in museum samples reveals inbreeding before the regression of Bombus veteranus. Apidologie 44 (2), 188-197.

Maebe, K., Meeus, I., Ganne, M., De Meulemeester, T., Biesmeijer, K., et al. (2015) Microsatellite analysis of museum specimens reveals historical differences in genetic diversity between declining and more stable Bombus species. PLoS One 10, e0127870.

Maebe, K., Meeus, I., Vray, S., Claeys, T., Dekoninck, W., et al. (2016) Genetic diversity of restricted wild bumblebees was already low a century ago. Sci. Rep. 6, 38289.

Martins, A.C., Goncalves, R.B., Melo, G.A.R. (2013) Changes in wild bee fauna of a grassland in Brazil reveal negative effects associated with growing urbanization during the last 40 years. Zoologia 30, 157-176.

Martins, A.C., Melo, G.A.R. (2010) Has the bumblebee Bombus bellicosus gone extinct in the northern portion of its distribution range in Brazil? J. Insect Conserv. 14, 207-210.

Martins, A.C., Silva, D.P., De Marco Jr., P., Melo, G.A.R. (2015) Species conservation under future climate change: the case of Bombus bellicosus, a potentially threatened South American bumblebee species. J. Insect Conserv. 19, 33-43.

Moure, J.S., Melo, G.A.R. (2012) Bombini Latreille, 1802. In Moure, J.S., Urban, D., Melo, G.A.R. (Orgs). Catalogue of Bees (Hymenoptera, Apoidea) in the Neotropical Region - online version. Available at http://www.moure.cria. org.br/catalogue. (Accessed 20 May 2016).

Nakagawa, S., Schielzeth, H. (2013) A general and simple method for obtaining $\mathrm{R}^{2}$ from generalized linear mixedeffects models. Methods Ecol. Evol . 4, 133-142.

Nei, M. (1978) Estimation of average heterozygosity and genetic distance from a small number of individuals. Genetics 89, 583-590.

Peakall, R., Smouse, F. (2006) GENALEX 6: Genetic Analysis in Excel. Population Genetic Software for Teaching and Research. Australian National University, Canberra, Australia.

R Development Core Team. (2008) R: A language and environment for statistical computing. $R$ Foundation for Statistical Computing http://www.R-project.org.

Santos Júnior, J.E., Santos, F.R., Silveira, F.A. (2015) Hitting an unintended target: Phylogeography of Bombus brasiliensis Lepeletier, 1836 and the first new Brazilian bumblebee species in a century (Hymenoptera: Apidae). PLoS One, 10 (5), e0125847.

Schmid-Hempel, R., Eckhardt, M., Goulson, D., Heinzmann, D., Lange, C., Plischuk, S., SchmidHempel, P. (2014) The invasion of southern South 
America by imported bumblebees and associated parasites. J. Anim. Ecol. 83, 823-837.

Soro, A., Quezada-Euan, J.J.G., Theodorou, P., Moritz, R.F.A., Paxton, R.J. (2017) The population genetics of two orchid bees suggests high dispersal, low diploid male production and only an effect of island isolation in lowering genetic diversity. Conserv. Genet. 18(3), 607-619.

Van Oosterhout, C., Hutchinson, W.F., Wills, D.P.M., Shipley, P. (2004) MICROCHECKER: software for identifying and correcting genotyping errors. Mol. Ecol. Notes 4, 535-538.

Wang, J. L. (2004) Sibship reconstruction from genetic data with typing errors. Genetics 166, 1963-1979.

Whitehorn, P.R., Tinsley, M.C., Brown, M.J.F., Darvill, B., Goulson, D. (2011) Genetic diversity, parasite prevalence and immunity in wild bumblebees. Proc. R. Soc. B. 278, 1195-1202.
Whitehorn, P.R., Tinsley, M.C., Brown, M.J.F.,Darvill, B., Goulson, D. (2014) Genetic diversity and parasite prevalence in two species of bumblebee. J. Insect Conserv. 18 (4), 667-673.

Zayed, A. (2009) Bee genetics and conservation. Apidologie 40, 237-262.

Publisher's note Springer Nature remains neutral with regard to jurisdictional claims in published maps and institutional affiliations. 